\title{
Practical training in family medicine in the Dalmatian hinterland: first-hand experience of four physicians
}

\author{
Minka Jerčić, Zorka Čizmić, Miona Vujević, Tina Puljiz
}

Department of Family Medicine School of Medicine in Split, Family Medicine Offices in Muć, Šestanovac Imotski and Runovići, Split, Croatia

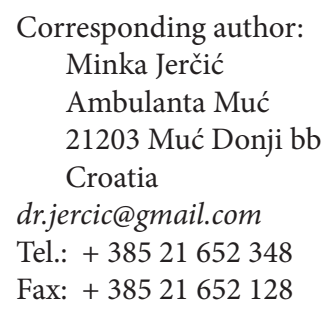

Copyright (C) 2012 by

Academy of Sciences and Arts of Bosnia and Herzegovina. E-mail for permission to publish: amabih@anubih.ba

\begin{abstract}
Four physicians working in private family medicine offices in Dalmatian Hinterland described their first hand experience of teaching sixthyear medical students. They supervised students during the 2010/2011 academic year, in an area that is economically undeveloped, rural, and where a number of people live in extended families. Although hesitant at first, the patients came to like the interaction with students, and later even yearned to provide students with as much information as possible. They also liked the letters that students had to write to them about their illness, because they could take them home and look for information without needing to see the doctor. The students showed diverse attitudes to different types of work in family medicine offices, mostly depending on their plans for future career. In general, they either complained or hesitated to perform duties that they did not fully master during earlier education, especially working with children. They needed several days to adapt to direct contact with the patients, and were more relaxed and cooperative when working in pairs than alone. The physicians themselves felt that they profited both from the novelty in the everyday routine and from the exchange of their experiences with the students. They liked their young colleagues and admitted they could not objectively review their own work, knowledge and skills.
\end{abstract}

Key words: Rural family medicine, Student practice, Mentoring in family medicine, Patient communication.

\section{Introduction}

We were given the opportunity to participate in practical training of sixth year medical students, during their family medicine course of the integrated undergraduate and graduate medical program at the School of Medicine in Split, in 2011 (1). The course is positioned at the end of the study program; it encompasses 11 hours of lectures, 42 hours of seminars, and 147 hours of practical work in family medicine offices in the city of Split, Split surroundings, and some of Adriatic islands for each student. The goal of the practice is to apply students' knowledge, skills and attitudes acquired in the previous phases of the study in a concrete clinical setting, with the duties of the family medicine physician. This was the first such experience for the three of us, while one had some previous experience. Family medicine practice in the 
Dalmatian Hinterland is somewhat specific when compared to the family practice in cities, coastal villages or islands. Dalmatian Hinterland is a part of south Croatia that is relatively large but sparsely populated. The population differs both economically and educationally from the rest of the country. It is still very rural and physicians care for both the pediatric and the adult patients. The changes affect the Hinterland at a slower pace compared to the more developed parts of the country. People also express their life philosophy in a different way, including their medical problems. Families in this area traditionally care for grandparents, and grandparents care for grandchildren and homes while parents work. It is mostly men have the jobs and they usually work far away from their homes and villages. In such a setting women take care of the field work, of the house, children and grandparents. This all results in a different relationship between the doctors and patients and their families (3).

Here we summarize our experiences and observations of working as supervisors of medical students.

\section{What did the students gain from the family medicine practice in a rural area?}

Encountering family practice at the Dalmatian Hinterland was a completely new experience for our students. The physicianpatient communication is closer and less formal. Even when we, as practitioners, came to this area first, we were advised by our older and wiser colleagues: "If you address them as You, they will answer as We." Similarly, an anecdote was passed on to all of us about an old man, who, a few days before he died, said to his physician: "Thank you for your care, but I have eaten my bread, my child!"

Intimacy and closeness between the physicians and the patients are common, because the patients do not talk only about their health problems, but also talk about other life issues and comment on various events, be it economical issues, politics or sports. In the Hinterland family physicians share important events with their patients, raise children together and share everyday lives. They are "ours" and we are "theirs", day or night, in the office, or on the streets (3). And so it is common when one of us goes to the shop to be asked: "Zorka, please, can I ask you about my disease". However, the students were confused by this practice, and many asked: "Don't they call you Mrs. Doctor?!" At the beginning of their practice with us, when a patient would leave the office, students would often comment: "What a character this man is!" It was then necessary to explain to all of the students that although we know most of our patients outside the practice, it is we ourselves who have to be professional and not endanger the deepest intimacy of our patients.

We also noticed a certain discomfort and uncertainty in the communication between the students and small children. It was necessary to insist that students examine a child, as the students were too often looking for ways and excuses of not do so. Some did accept the challenge and examined children, but with great apprehension and insecurity. We believe the reason behind this is that they did not expect to take care of small children, as children are usually covered by primary pediatric offices in larger cities. Perhaps they were also reluctant to work with children because they were a bit afraid of their skills and knowledge. They complained that it was difficult to get sensible answers from children, that their answers were unreliable, and that it was often difficult to establish the desired cooperation during the check-up. This made us think that family physicians and primary care pediatricians should provide a more coordinated pediatrics teaching.

All of the students were also given the opportunity to tour the area with their su- 
pervisors in order to gain insight into the socio-economic conditions of patients. Surprisingly, they did not show a great passion for field work - something that is expected from physicians whose job is to provide health care for all. We do not know the reasons for this reluctance; perhaps it is related to the current system of education, where formal knowledge predominates over practical and field work. This problem definitely requires attention and different educational approach.

Since the distance from the nearest hospital is about $30 \mathrm{~km}$ or more, we are more likely to perform minor surgeries and procedures (suturing minor wounds, removing foreign bodies from the eye, placing a urinary catheter) than our colleagues in city offices. The possibility to refresh their skills made some students happy, while others again retreated in the background. We observed that this largely depended on the students' interests in their future careers. Those who saw themselves as future surgeons enjoyed these opportunities, while others needed to be specifically encouraged and stimulated. Some had the opportunity to accompany a patient with a heart attack to the closest hospital, and observe how their supervisors coped in emergencies. They learned that we, even after years of experience, have our professional dilemmas and very often need to discuss them with colleagues. Overall, all students who did try to perform the tasks were later proud and happy. Those who were reluctantly engaged in practical work for various reasons later complained of missed opportunities (Table 1).

\section{What did the supervisors gain from the work with students?}

Working with students was certainly refreshing in our line of work. Young people always bring cheerfulness, encouragement, even when they are not too keen to perfect their skills. Wishing to excel in our teach- ing assignments and to show students some useful skills for the future, we had to change our routine practice to some extent (Table 1). We went more thoroughly through patients' physical exams and history taking for the sake of our students, although we were very familiar with the medical histories of our patients. We insisted on proper and full physical examination each visit, even if we had seen the patient just a few days before the students arrived. The Drug Register was always there on the table to help students, although they often realized that it could not always help them as some of the patients would come and ask for "small white pills". We also had the Therapeutic Manual to look up the generic names of drugs, the group they belong to, their main characteristics, and how and when to use them. We discussed all the other materials we had at our hands, from the treatment guidelines to the leaflets about new medications brought in by the representatives of different pharmaceutical companies.

Working with students opened the possibility of interactive learning between us (4), where knowledge and experience of a supervisor was exchanged with the students' fresh knowledge from the latest textbooks and lectures. Most of this matter related to changes in the therapeutic approach: we were happy to show that we kept up to date with new diagnostic technologies, and the students were happy to help with the computer systems in our offices (Table 1).

We had the impression that the students were truly interested in the practice. However, when it comes to the diaries the students had to keep during the practical classes, we are of mixed opinion. The diaries were part of examination in family medicine, and required from the students to fill in his or her patients, with diagnoses for the entire practice. Two of us believe that the diaries brought about a higher responsibility to the students, while two believe it hinders 
Table 1 Summary of teaching experience of four family medicine physicians from a Southern Croatian rural area

\begin{tabular}{|c|c|c|c|}
\hline Subjects & Benefits & Setbacks & Problems \\
\hline Physicians & $\begin{array}{l}\text { - Teaching practice } \\
\text { - Refreshment of routine } \\
\text { - Opportunity to review } \\
\text { professional issues } \\
\text { - Strengthening of ties with the } \\
\text { University } \\
\text { - Better communication among } \\
\text { family medicine physicians } \\
\text { - Increase of respect among } \\
\text { patients towards physicians }\end{array}$ & $\begin{array}{l}\text { - Takes longer to see patients } \\
\text { - Patient confidentiality issues } \\
\text { - Need for additional } \\
\text { organizational efforts related } \\
\text { to education (diary, letters, } \\
\text { OSCE, test questions, etc.) }\end{array}$ & $\begin{array}{l}\text { - No formal/systematic } \\
\text { preparation for teaching } \\
\text { - Lack of tradition and lack } \\
\text { of insistence on objective } \\
\text { evaluation } \\
\text { - Short time for analysis and } \\
\text { evaluation of students' work } \\
\text { - Matching actual patient and } \\
\text { students' needs }\end{array}$ \\
\hline Students & $\begin{array}{l}\text { - Rural environment/specific } \\
\text { population } \\
\text { - Full patient care } \\
\text { - Direct and individual supervisor- } \\
\text { student relationship } \\
\text { - Practicing independently } \\
\text { - Opportunity to do minor surgery }\end{array}$ & $\begin{array}{l}\text { - Travel and housing } \\
\text { arrangements, with } \\
\text { insufficient financing } \\
\text { - Time and effort commitment } \\
\text { with respect to travel and } \\
\text { accommodation }\end{array}$ & $\begin{array}{l}\text { - Communication with patients } \\
\text { - Communication with children } \\
\text { - Lack of interest in home visits } \\
\text { - Lack of interest in family } \\
\quad \text { medicine as a career }\end{array}$ \\
\hline
\end{tabular}

the students, as it makes them focus on the diary instead on the everyday work (Table 1). We all believe that the diary writing and student engagement depended on the personality of each one of us, the burden of ordinary activities during working hours, and on our own previous experiences with being students (4).

\section{What did the patients gain from the students?}

Since this was the first year that students had practical classes in most of our offices, the patients were initially confused. Some even to the extent that they expressed fear and uncertainty, and were reluctant to come back to the office for few weeks. Perhaps this was a sudden change for them - they did not have "my doctor" (3) to whom they had to say something very important and confidential at that particular time. However, most of them quickly accepted the students, showed extreme benevolence and understanding that this was an important part of learning for the future work of the students. In the end they all wanted to help by readily responding to students' inquiries and wishing them all the best in their own future practices. Perhaps preparing the patients should be done in advance, with thorough information on how the practice is important for education of young physicians.

We were particularly impressed with the letters that students had to write to the selected patients. This letters had to contain information about the patient's diseases and ways to improve their health. The practice of writing letters to the patients was introduced as a part of teaching and examination in the family medicine course in the 2010/11 academic year. During history taking of patients whom they later had to write letters to, some students rather awkwardly approached the patients, leaving some of the patients with the impression that they may have disclosed too much sensitive information. We quickly dispersed their anxiety and explained further the purpose of many questions during the interview. When the patients received their letters, they were thrilled. Here we present some of their typical comments:

- "I have always wanted that someone explains everything to me in this way!" 
- "Every now and then, I go back to the letter and read it, and it helps me in my disease."

Such comments made some of us think to take on this practice ourselves and write a letter to our patients from time to time, so that they can recall the advice given even without the direct contact with the doctor. In selecting the patients for students, the supervisors again had a different approach. We usually suggested patients with regard to either their peculiarities or the problems they had. Some of the students chose patients on their own, mainly according to the diagnoses they found interesting or for the simplicity of the case. This turned out to be a great lesson for the students, as simple diagnoses were deceptive, and not often easy to manage and resolve in real-life patients.

\section{Evaluation of students' work}

At the end of the practice, we had to evaluate the students' work. Some of us had their doubts about this task (Table 1). It should be emphasized that the total score for colleagues and students was very positive: the students attended practical classes regularly, they showed interest and became true members of the team, and at certain moments displayed exceptional sensitivity to patients and their fates (The compassion and their interest in medical practice were more evident if they previously had similar experiences in their family or among friends.). The rating addressed 5 components of the student's work: regularity of attendance, regularity of keeping the diary, interest in work, relationship with patients, knowledge and learning; with each having a maximum number 4 points. A rating structured as this caused dilemmas for us. First, we tried to assess our own contribution during their stay in the practice. Some of thought we could have and should have given more, and so we decided to be "less strict". In assessing, the positive overall impression of the group of students biased us in grading the students individually.

Sometimes we were expecting a little more initiative on the students' part. There were also those that were late with their assigned tasks, but we found it hard to lower their point's cause of this. We were gentle in evaluating all of the parts, and the regularity of attendance was hundred percent, for the students had no place to go in such a small village. We chose to look for good characteristics and reward them. We believe this will have a greater impact on the students, than would punishment the errors or rating the skills and knowledge they were supposed to acquire before our course. However, the question remains on how to achieve greater objectivity in future work and should we be the ones evaluating at all. Perhaps if next time we told the young colleagues immediately what we expect from them, i.e. what segment of work we consider particularly important, could help us avoid empathy and subjectivity. In addition, we think that assessing could make each individual student perceive what he or she is good at and where to put more effort in order to be a better doctor. The grading also gives certain seriousness to practical classes. We do understand that the students wish to experience certain leisure in the practical classes and the field trips, despite it being the very beginning of their independent work.

\section{Comments and suggestions}

There were five male and one female student in the outpatient clinic in Muć, in two groups, three in one and two in the other. There were three students in Šestanovac, Runovići and Imotski. We think that the number of students was too high for Muć. Two or three students develop completely different dynamics during work than a single one. When paired, students mutu- 
ally complemented each other in taking the patients' history and examining them. This dynamics may be useful and encouraging, although it prevents individual work of the student with a patient. Larger groups of students disturb the privacy of the patients making them unconformable and wary. Duration of the practice in an outpatient clinic may benefit from additional time, as it takes some time for students to adjust to the everyday work, and enable them to ask questions freely and. The students also change the whole routine of the clinic work and at some moments during the day, most of us felt we wished to have been alone. However, we would have then missed the time at the end of the day, when we discussed the patients and activities of the day. This kind of interaction between students and us started in the second week of their stay at the office.

We believe the usefulness of staying in a family medicine practice would be higher if the continuity of visits was ensured during more years of study, not just in the final year. In the first or the second year of their studies, such visits could just have the aim of experiencing the atmosphere of future work and would not need to be longer than two or three days. Since students' knowledge and skills increase during their studies, attending family medicine offices should increase proportionally. It could also be beneficial if the same students came to the same supervisors each year.

Most future doctors in Croatia will start their professional job in a family medicine practice and many will stay there for their whole professional life. It was therefore peculiar to discover that only one out of five students in our practices expressed the wish to work as a family physician. This is another reason to further develop field work as a part of family medicine course, as colleagues from all over the world report similar information, noting that the students' attitudes about being a family physician change after actual practice in such clinics $(5,6)$. Working with young people, especially with our future colleagues, was challenge, satisfaction and responsibility $(4,6)$. It was a privilege to share and gain insight into their plans and wishes for their future. We noticed, however, that they somehow lacked motivation and enthusiasm. They also shared with us their concern that they did not perhaps show their full potential and skills (Table 1). We need to re-think education in family medicine so that the generations of doctors to come should be fully competent and qualified to deal with the challenges of future (7). Our experience suggests that the practice in rural areas such as Dalmatian Hinterland is of utmost importance for this goal.

Acknowledgment: We thank Dr Ivančica Pavličević for trust and support, Professor Matko Marušić for giving us the chance to teach, for his encouragement and insistence that we write our experiences, and to Professor Ana Marušić for critical revision of the article.

Conflict of interest: The authors declare that they have no conflict of interest. This article was not sponsored by any external organisation.

Authors' contribution: All four authors contributed to Conception and design; Acquisition, analysis and interpretation of data; Drafting the article; and Revising it critically for important intellectual content.

\section{References}

1. Marušić $M$, editor. Integrated study program of medicine at Medical school in Split [in Croatian]. Split: Medical School in Split; 2011. (ISBN 978953-7524-12-8)

2. Marinov N. 175 years of education in Muć [in Croatian]. In: Marinov N, editor. Zbornik o Zagori, knjiga 6. Split: Općina Muć; 2002. p. 47-55. (ISSN 1331-6370)

3. Rakel RE. Family medicine physician [in Croatian]. In: Katić M, editor. Zagreb: Naklada Ljevak; 2005. p. 3-19.

4. Vrcić-Keglević M. Family/general medicine physician as teacher [in Croatian]. Jakšić Ž, editor. 
Ogledi o razvoju opće/obiteljske medicine. Zagreb: HUOM; 2001. p. 214-20.

5. Larsen K, Perkins D. Training doctors in general practices. A review of the literature. Aust J Rural Health. 2006;14.173-7.

6. Thistlethwaite JE, Kidd MR, Hudson JN. General practice: a leading provider of medical stu- dent education in the 21st century? Med J Aust. 2007;187(2):124-8.

7. Deaville JA, Wynn-Jones J, Hays RB, Coventry PJ, McKinley RK, Randall-Smith J. Perceptions of UK medical students on rural clinical placements. Rural Remote Health. 2009;9(2):1165. Available from: http://www.rrh.org.au/publishedarticles/ article_print_1165.pdf 